\title{
Vasospasm Following Aneurysmal Subarachnoid Hemorrhage
}

\author{
Eduardo Vieira and Hildo Azevedo-Filho
}

\subsection{Introduction}

Majority of morbidity and mortality due to aneurysmal subarachnoid hemorrhage (aSAH) is secondary to cerebral ischemia. Classically, the angiographic arterial narrowing following aSAH has been termed as angiographic vasospasm, which may or may not lead to clinical manifestations and cerebral ischemia, in which case it would be called symptomatic vasospasm. This concept has recently been questioned. Not always angiographic vasospasm leads to cerebral ischemia, which, in turn, may occur in a territory different from the one irrigated by the narrowed artery or even in the absence of any angiographic vasospasm, i.e., cerebral ischemia that occurs late (days after aSAH) cannot be attributed solely to the arterial narrowing seen on angiography [1]. Currently, the term "delayed cerebral ischemia" (DCI) has been proposed to replace the previously used "symptomatic vasospasm." The clinician should be able to recognize and differentiate the radiological vasospasm from the clinical worsening secondary to DCI, whose etiology is multifactorial and includes angiographic arterial narrowing (Fig. 29.1). Alternative mechanisms have been proposed and include microvascular spasm and failure of cerebral blood flow (CBF)

E. Vieira $(\bowtie) \cdot H$. Azevedo-Filho Department of Neurological Surgery, Hospital da Restauracao, Recife, Brazil autoregulation, microthrombosis and microembolism, cortical spreading depolarization and ischemia, and delayed neuronal apoptosis resulting from acute brain injury. A more extensive review of the pathophysiology of DCI is out of the scope of this review.

DCI is a diagnosis of exclusion. When there is neurological deterioration, the diagnosis of DCI can only be established when causes like hydrocephalus, hyponatremia, infection, and bleeding are ruled out, and the introduction of hypertensive therapy or endovascular treatment leads to clinical improvement. In the next sessions, we will discuss about the risk factors, prevention, monitoring, and treatment of DCI.

\subsection{Risk Factors}

The hemoglobin $(\mathrm{Hb})$ in subarachnoid space is a very important factor that triggers vasospasm and DCI. $\mathrm{Hb}$ is extremely toxic in the subarachnoid space leading to the rapid activation of cellular adhesion molecules (CAMs) on luminal surface of endothelial cells, enabling macrophages and neutrophils to penetrate into subarachnoid space, where they will phagocytize RBCs and free $\mathrm{Hb}$. After this process, however, macrophages and neutrophils are trapped in the subarachnoid space due to the lack of lymphatic drainage in CNS (central nervous system) and to the difficulty in CSF drainage resulting from aSAH. Between 

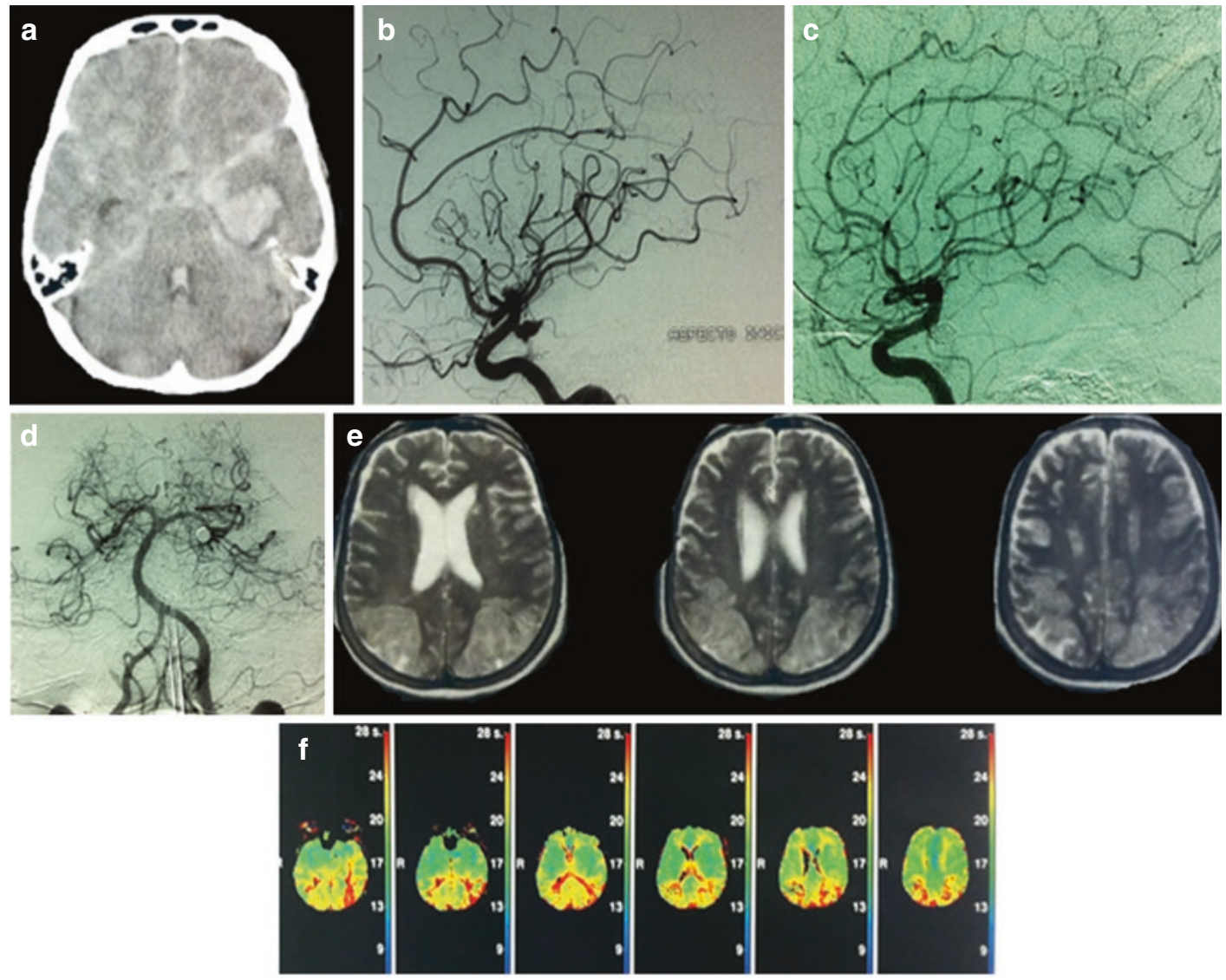

Fig. 29.1 This 72-year-old female patient with a typical history of sudden headache associated with disorientation (HH III) was admitted to hospital. (a) CT scan showed a Fisher III with medial temporal hematoma. (b) Angiography performed $24 \mathrm{~h}$ after admission confirmed an ICA-PCom aneurysm, which was coiled. The patient did well until the ninth day after bleeding, when she became drowsy and unresponsive. (c) and (d) Angiography

2 and 4 days, these cells die and disintegrate, releasing intracellular endothelin and free oxygen radicals, leading to vasoconstriction and arteriopathy. That said, it is easy to realize that key factor for DCI is quantity of blood that stays in subarachnoid space.

Quantity of blood in subarachnoid space can be measured by cranial CT and based on this measurement; scales for predicting the possibility of vasospasm were developed. The most widespread and used is the one proposed by Fisher et al. (Table 29.1) [2]. Analyzing this performed on the tenth day after bleeding did not reveal vasospasm, and hypertensive therapy was maintained. (e) MRI showed ischemic areas predominantly in the territory of posterior cerebral arteries. (f) Perfusion study revealed a decreased $\mathrm{CBF}$ and $\mathrm{CVF}$, consistent with irreversible ischemia. The cause of DCI is multifactorial, although it's associated with vasospasm, it can occur in the absence of angiographic vasospasm

scale, one can notice that patients at highest chance to have vasospasm and DCI are those classified as grade 3, and within this group, there is a wide possible range in quantity of blood present in subarachnoid space, creating a vital variation in probability of developing DCI and vasospasm in patients of the same group of the scale (Fig. 29.2), i.e., the Fisher scale fails to identify those patients at highest risk of developing DCI. Wilson et al. proposed a new scale (BNI scale) (Table 29.1) where the thickness of the clot present in the subarachnoid space was evaluated, 
Table 29.1 Comparison between Fisher and BNI scales

\begin{tabular}{|l|l|l|l|l|l} 
Scale & $\begin{array}{l}\text { Grade } \\
1\end{array}$ & Grade 2 & Grade 3 & Grade 4 & Grade 5 \\
\hline Fisher & $\begin{array}{l}\text { No } \\
\text { blood }\end{array}$ & $\begin{array}{l}\text { Clot less than } \\
1 \mathrm{~mm} \text { thick }\end{array}$ & $\begin{array}{l}\text { Clot more than } \\
1 \mathrm{~mm} \text { thick }\end{array}$ & $\begin{array}{l}\text { Grade 1 or 2 and associated intracerebral } \\
\text { hematoma or hemoventricle }\end{array}$ & - \\
BNI & $\begin{array}{l}\text { No } \\
\text { blood }\end{array}$ & $\begin{array}{l}\text { Clot less than } \\
5 \mathrm{~mm} \text { thick }\end{array}$ & $\begin{array}{l}\text { Clot } 5-10 \mathrm{~mm} \\
\text { thick }\end{array}$ & Clot 10-15 $\mathrm{mm}$ thick & $\begin{array}{l}\text { Clot more than } \\
15 \mathrm{~mm} \text { thick }\end{array}$ \\
\hline
\end{tabular}
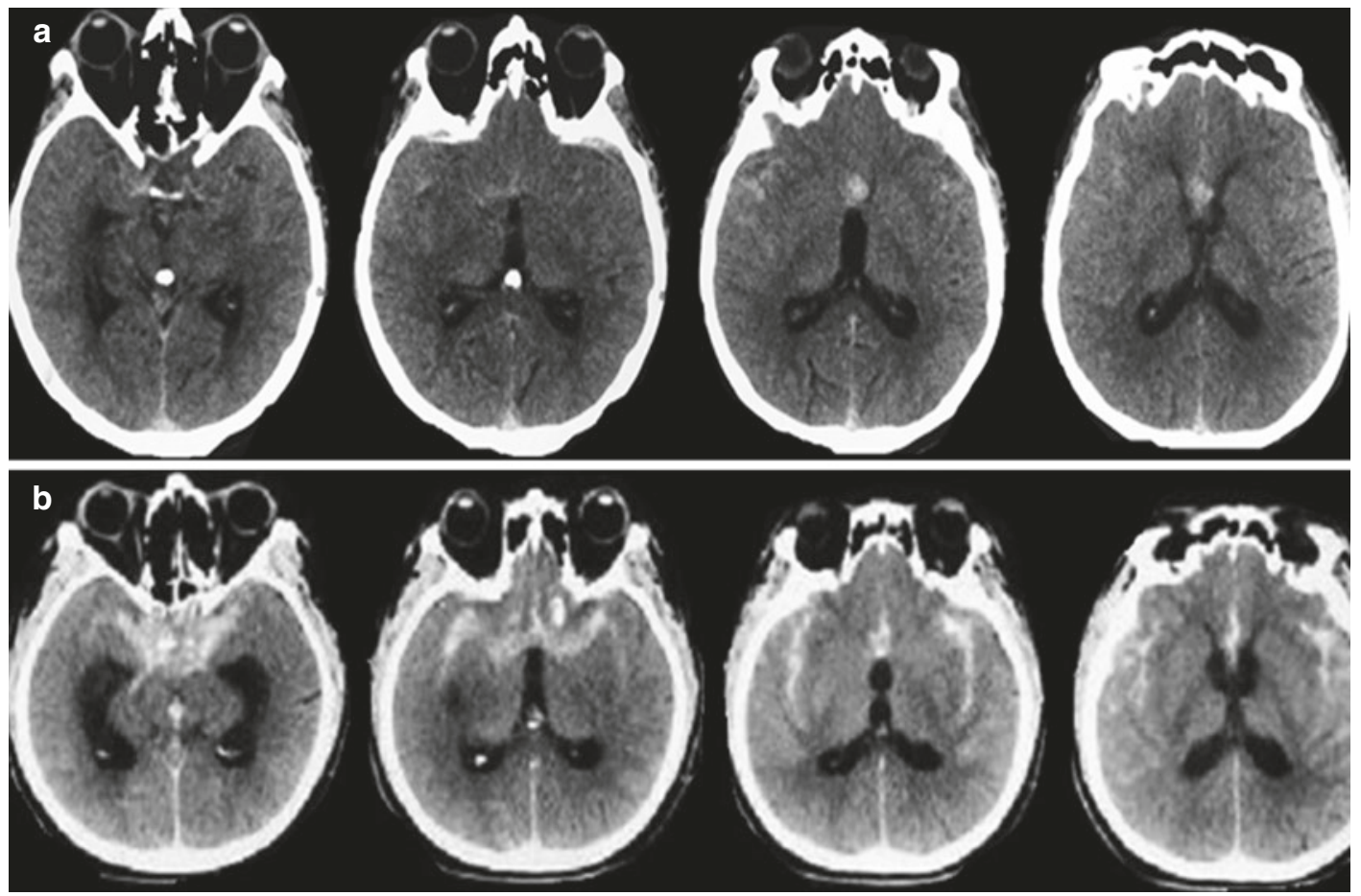

Fig. 29.2 Two patients (A and B) with a Fisher grade 3 aSAH. There is a significant difference between the volumes of blood present in the subarachnoid space between these two patients. Although classified within the same subgroup, patient B has a greater chance of developing vasospasm and DCI with a consequent poor outcome stratifying those patients grouped as grade 3 in Fisher scale and showing that the size of the thickness of the clot in subarachnoid space is directly proportional to risk of vasospasm and DCI (Table 29.2) [3].

Other risk factors for having the vasospasm and DCI are Hunt-Hess grades 4 and 5, history of hypertension, smoking, early angiographic vasospasm, and young age ( $<35$ years) [4-6]. Hypovolemia is an important and avoidable risk factor that can occur due to cerebral salt-wasting syndrome (CSWS) and should be avoided at all costs.

\subsection{Prevention}

One of the most important factors in the prevention of DCI is to maintain normovolemia. It is important to emphasize, however, that there is no space for prophylactic hypervolemic therapy, as it does not result in increased CBF nor in better clinical results [7].

The administration of nimodipine, a calcium channel blocker, for 21 days, starting from the moment of admission is probably the only class I recommendation on most recent guiding principle for the management of aSAH from AHA/ 
Table 29.2 Differences in the incidence of DCI between the BNI and Fisher scales in 218 patients

\begin{tabular}{|l|l|l|l|l|}
\hline \multicolumn{2}{|l|}{ Fisher scale } & & \multicolumn{3}{|l|}{ BNI scale } \\
\hline $\begin{array}{l}\text { DCI } \\
(\%)\end{array}$ & $\begin{array}{l}\text { Distribution } \\
(\%)\end{array}$ & Grade & $\begin{array}{l}\text { Distribution } \\
(\%)\end{array}$ & $\begin{array}{l}\text { DCI } \\
(\%)\end{array}$ \\
\hline 0 & 0 & 1 & 3.7 & 0 \\
\hline 15 & 6 & $\mathbf{2}$ & 33 & 13 \\
\hline 23 & 83.5 & $\mathbf{3}$ & 44.5 & 22 \\
\hline 6 & 7.3 & $\mathbf{4}$ & 12.4 & 30 \\
\hline- & - & $\mathbf{5}$ & 6.4 & 50 \\
\hline
\end{tabular}

Using the classification of Fisher, $83.5 \%$ of patients are classified as grade 3 , and within this subgroup, the greater the thickness of the clot on the CT scan, the greater the chance of DCI

ASA [8]. The drug should be administered orally with $60 \mathrm{mg}$ that is given every $4 \mathrm{~h}$, with a decrease in the relative risk (RR) for DCI of $18 \%(95 \%$ $\mathrm{CI}=7-28 \%)$ and a number necessary to treat (NNT) of $13[9,10]$. It is important to emphasize that there is no benefit if the drug is started more than $72 \mathrm{~h}$ after bleeding. Importantly, the medication does not prevent vasospasm. It is believed that nimodipine acts through neuroprotective mechanisms, stabilizing cell membranes, decreasing the risk of DCI, and improving patients' outcomes.

Endothelin is a potent vasoconstrictor peptide, mediator of cerebral vasospasm. It is formed through a wide diversity of cells, such as leukocytes and macrophages in the CSF as described above. The use of the inhibitor of endothelin clazosentan was evaluated in different studies.

The results showed that the drug reduces the incidence of angiographic vasospasm in a dosedependent manner, with no influence, however, on the incidence of DCI and morbidity or mortality [11-14]. This clinical-radiological dissociation is one more data to support the theory that vasospasm cannot, solely, be responsible for DCI.

Statins and magnesium sulfate have been proposed for the prevention of vasospasm and DCI. Two randomized controlled trials (RCTs), the STASH study [15], for statins, and the MASH-2 study [16], for magnesium sulfate, showed that the use of these drugs is of no benefit on the prophylaxis of DCI. Although there is no indication of starting, patients who already use statins may continue the medication after aSAH.

\subsection{Monitoring and Diagnosis}

The best way to assess and monitor a patient at risk of vasospasm and DCI is through seriated clinical examinations. If there are a decrease level of consciousness and also an onset of new focal deficits, it should prompt investigation in order to exclude hydrocephalus, rebleeding, infection, and hyponatremia. If these entities are all excluded, the diagnosis of DCI is made, and treatment should be instituted as soon as possible.

Critical patients, especially those who already present in coma, are harder to monitor and to evaluate. Because of its noninvasiveness and wide availability, transcranial Doppler ultrasonography (TCD) is the most commonly employed auxiliary method. Although it has high specificity, it lacks sensibility for the development of DCI, especially for territories other than the middle cerebral artery (MCA) [17]. One should never rely solely on TCD to rule out vasospasm and DCI.

In these cases, other auxiliary methods that can be employed are the CT angiography (CTA) and CT perfusion. The CTA has excellent accuracy (98-100\%) for severe vasospasm (narrowing $>50 \%$ ) when compared to digital subtraction angiography (DSA) but loses sensitivity in mild to moderate vasospasm (57-85\%). CT perfusion complements CT angiography demonstrating perfusion abnormalities, even in the absence of proximal vasospasm. Three parameters are calculated, which, if considered together, can guide the treatment of vasospasm and DCI in critically ill patients:

- Mean transit time (MTT) is the average length of transit time for blood that is located in particular area of the brain. It is defined in seconds.

- Cerebral blood volume (CBV) is the whole blood volume that stays in a certain volume of the brain, which is usually measured in $\mathrm{ml} / 100 \mathrm{~g}$.

- Cerebral blood flow (CBF) is the volume of blood that flows in a certain volume of the brain, which is usually measured in $\mathrm{ml} / 100 \mathrm{~g} /$ $\min$. 
Table 29.3 Variables to be observed on CT perfusion and treatment to be adopted

\begin{tabular}{|l|l|l|l|l|}
\hline MTT & CBV & CBF & Meaning & Treatment \\
\hline$\uparrow$ & $\leftrightarrow$ or & $\leftrightarrow$ & $\begin{array}{l}\text { Perfusion } \\
\text { abnormality } \\
\text { adequately } \\
\text { compensated by } \\
\text { cerebral } \\
\text { autoregulation }\end{array}$ & $\begin{array}{l}\text { Close } \\
\text { observation }\end{array}$ \\
\hline$\uparrow$ & $\leftrightarrow$ or & $\downarrow$ & $\begin{array}{l}\text { Perfusion } \\
\text { abnormality with } \\
\text { reversible cerebral } \\
\text { ischemia } \\
\text { (penumbra) }\end{array}$ & $\begin{array}{l}\text { Hypertensive } \\
\text { and/or } \\
\text { endovascular }\end{array}$ \\
\hline$\uparrow$ & $\downarrow$ & $\downarrow$ & $\begin{array}{l}\text { Perfusion } \\
\text { abnormality with } \\
\text { irreversible } \\
\text { cerebral ischemia }\end{array}$ & Not indicated \\
\hline$\uparrow$ & $\downarrow$ & & \\
\hline
\end{tabular}

The MTT is the most sensitive parameter for DCI and vasospasm and should be the first to be evaluated when analyzing the CT perfusion. Increase in MTT demands strict observation of CBV and CBF (Table 29.3) [18]. MRI with diffusion and perfusion sequences is also a good alternative but more expensive, time-consuming, and less available. Although DSA is still defined as a gold standard auxiliary method for diagnosis of vasospasm, its use must be reserved when endovascular treatment of DCI is considered.

\subsection{Treatment}

Once the diagnosis of DCI is confirmed, appropriate therapy should be started promptly. Classically, the first-line treatment has been the triple-H treatment which includes hypertension, hemodilution, and hypervolemia. Initial goal should be to raise the mean arterial pressure (MAP) by $20 \%$ from baseline. If this measure fails, sequential increases of $10 \%$ are induced until clinical response is achieved (with a limit of $220 \mathrm{mmHg}$ and $120 \mathrm{mmHg}$ for systolic and diastolic blood pressure, respectively). During this hypertensive therapy, close monitoring of cardiac function is necessary, especially in elderly or high Hunt-Hess grade patients, because they are at greater risk of cardiomyopathy related to aSAH. If, after 6-12 h of triple-H therapy, there is no clinical improvement, then endovascular therapy is indicated.

Recently, the utility of each component from triple- $\mathrm{H}$ treatment has been evaluated. Of the three components, the more beneficial one is hypertension, which acts in increasing oxygenation and CBF. Hypervolemia and hemodilution may increase the CBF but have been associated with decreased cerebral tissue oxygenation (PtiO2) $[19,20]$. This effect seems to be associated with a decrease in $\mathrm{Hb}$ levels caused by hemodilution. During triple-H therapy, hemoglobin concentration should be monitored and should not fall below 9-10 g/dl. In critically ill patients, ideally $\mathrm{PtiO} 2$ should be monitored.

Once indicated, endovascular therapy should be performed as soon as possible. Balloon angioplasty is the preferred method and should be used whenever feasible. Usually it is reserved for proximal vasospasm, including supraclinoid ICA, proximal ACA (mainly A1), proximal MCA (M1, M2), vertebral artery (VA), basilar artery (BA), and proximal PCA (P1, P2). Early angiographic studies (baseline) must be assessed before proceeding with angioplasty in order to avoid dilatation of a hypoplastic vessel. Angioplasty at the location of recent clipping of a ruptured aneurysm is not safe and carries high risk of vessel rupture [21]. Intra-arterial infusion of vasodilators (papaverine, milrinone, or, preferably, nimodipine which is a calcium channel blockers) has a modest and ephemeral benefit and should be used in conjunction with balloon angioplasty or in the case of distal vasospasm, in which case angioplasty is not feasible.

\section{References}

1. Brown RJ, Kumar A, Dhar R, et al. The relationship between delayed infarcts and angiographic vasospasm after aneurysmal subarachnoid hemorrhage. Neurosurgery. 2013;72(5):702-7.

2. Fisher CM, Kistler JP, Davis JM. Relation of cerebral vasospasm to subarachnoid hemorrhage visualized by computerized tomographic scanning. Neurosurgery. 1980;6:1-9.

3. Wilson DA, Nakaji P, Abla AA, et al. A simple and quantitative method to predict symptomatic vasospasm after subarachnoid hemorrhage based on 
computer tomography: beyond the Fisher scale. Neurosurgery. 2012;4:721.

4. Frontera JA, Claassen J, Schmidt JM, et al. Prediction of symptomatic vasospasm after subarachnoid hemorrhage: the modified fisher scale. Neurosurgery. 2006;59:21-7.

5. Rabb CH, Tang G, Chin LS, et al. A statistical analysis of factors related to symptomatic cerebral vasospasm. Acta Neurochir. 1994;127:27-31.

6. Lasner TM, Weil RJ, Riina HA, et al. Cigarette smoking-induced increase in the risk of symptomatic vasospasm after aneurysmal subarachnoid hemorrhage. J Neurosurg. 1997;87(3):381-4.

7. Lennihan L, Mayer SA, Fink ME, et al. Effect of hypervolemic therapy on cerebral blood flow after subarachnoid hemorrhage: a randomized controlled trial. Stroke. 2000;31:383-91.

8. Connolly ES, Rabinstein AA, Carhuapoma JR, et al. Guidelines for the management of aneurysmal subarachnoid hemorrhage: a guideline for healthcare professionals from the American Heart Association/American Stroke Association. Stroke. 2012;43:1711-37.

9. Pickard JD, Murray GD, Illingworth R, et al. Effect of oral nimodipine on cerebral infarction and outcome after subarachnoid haemorrhage: British aneurysm nimodipine trial. BMJ. 1989;298:636-42.

10. Rinkel GJE, Feigin VL, Algra A, et al. Calcium antagonists for aneurysmal subarachnoid haemorrhage. Cochrane Database Syst Rev. 2005;(1):CD000277.

11. MacDonald RL, Kassell NF, Mayer S, et al. Clazosentan to overcome neurological ischemia and infarction occurring after subarachnoid hemorrhage (CONSCIOUS-1): randomized, double-blind, placebo-controlled phase 2 dose-finding trial. Stroke. 2008;39(11):3015-21.

12. MacDonald RL, Higashida RT, Keller E, et al. Clazosentan, an endothelin receptor antagonist, in patients with aneurysmal subarachnoid haemorrhage undergoing surgical clipping: a randomised, double-blind, placebo-controlled phase 3 trial (CONSCIOUS-2). Lancet Neurol. 2011;10(7):618-25.
13. MacDonald RL, Higashida RT, Keller E, et al. Randomized trial of clazosentan in patients with aneurysmal subarachnoid hemorrhage undergoing endovascular coiling. Stroke. 2012;43(6):1463-9.

14. Vergouwen MD, Algra A, Rinkel GJ. Endothelin receptor antagonists for aneurysmal subarachnoid hemorrhage: a systematic review and metaanalysis update. Stroke. 2012;43(10):2671-6.

15. Kirkpatrick PJ, Tuner CL, Smith C, Hutchinson PJ, Murray GD. Simvastatin in aneurysmal subarachnoid haemorrhage (STASH): a multicenter randomized phase 3 trial. Lancet Neurol. 2014;13(7):666-75.

16. Dorhout Mees SM, Algra A, Vandertop WP, et al. Magnesium for aneurysmal subarachnoid haemorrhage (MASH-2): a randomised placebo-controlled trial. Lancet. 2012;380(9836):44-9.

17. Lysakowski C, Walder B, Costanza MC, et al. Transcranial Doppler versus angiography in patients with vasospasm due to a ruptured cerebral aneurysm: a systematic review. Stroke. 2001;32:2292-8.

18. Binaghi S, Colleoni ML, Maeder P, et al. CT angiography and perfusion $\mathrm{CT}$ in cerebral vasospasm after subarachnoid hemorrhage. AJNR Am J Neuroradiol. 2007;28(4):750-8.

19. Dankbaar JW, Slooter AJ, Rinkel GJ, et al. Effect of different components of triple-H therapy on cerebral perfusion in patients with aneurysmal subarachnoid haemorrhage: a systematic review. Crit Care. 2010;14(1):R23.

20. Raabe A, Beck J, Keller M, et al. Relative importance of hypertension compared with hypervolemia for increasing cerebral oxygenation in patients with cerebral vasospasm after subarachnoid hemorrhage. J Neurosurg. 2005;103(6):974-81.

21. Linskey ME, Horton JA, Rao GR, et al. Fatal rupture of the intracranial carotid artery during transluminal angioplasty for vasospasm induced by subarachnoid hemorrhage. Case report. J Neurosurg. 1991;74(6):985-90.

Open Access This chapter is licensed under the terms of the Creative Commons Attribution 4.0 International License (http://creativecommons.org/licenses/by/4.0/), which permits use, sharing, adaptation, distribution and reproduction in any medium or format, as long as you give appropriate credit to the original author(s) and the source, provide a link to the Creative Commons license and indicate if changes were made.

The images or other third party material in this chapter are included in the chapter's Creative Commons license, unless indicated otherwise in a credit line to the material. If material is not included in the chapter's Creative Commons license and your intended use is not permitted by statutory regulation or exceeds the permitted use, you will need to obtain permission directly from the copyright holder.

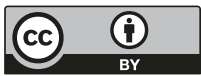

